\title{
An assessment of the diabetic knowledge of school teachers
}

\author{
A J BRADBURY AND C S SMITH
}

\author{
Department of Child Health, Alder Hey Children's Hospital, Liverpool
}

SUMMARY Ninety seven teachers of diabetic pupils in Liverpool completed a questionnaire designed to assess their knowledge of diabetes mellitus and the sources from which they had obtained information. The survey aimed to evaluate their understanding and to aid in planning an alternative policy of teacher education. Only 24 teachers $(25 \%)$ seemed to have adequate understanding of diabetes and there was little knowledge of recognition and treatment of emergency diabetic problems and aspects of diet. Most information had been obtained from either diabetic pupils or their parents and not from medical or nursing personnel.

Diabetes mellitus affects approximately $1 \cdot 42 / 1000$ children up to age 16 years in Britain. ${ }^{1}$ It may be controlled but not cured and requires management throughout the day, including the time spent in school. Problems associated with loss of control such as hypoglycaemia may arise during school hours, sometimes with little warning, and emotional difficulties of diabetic children may affect attendance and academic performance. If a child with diabetes is to participate fully in school activities and is to achieve his educational potential his teachers must have a working knowledge of those aspects of diabetes that affect school life. The responsibility for this should rest with the community child health services through the school doctors and nurses. A recent study ${ }^{2}$ showed that teachers were poorly informed about the function of the child care support services and lacked expectation of help from school doctors concerning pupils with chronic illness.

At this hospital it has not been the routine practice to contact the schools attended by diabetic children. The community specialist (child health) receives a copy of the initial ward discharge summary and subsequent letters regarding problems related directly to educational matters. During their structured diabetic education the parents receive copies of the British Diabetic Association (BDA) leaflet DH127, The diabetic at school and a similar leaflet prepared by the hospital. It is intended that these leaflets be passed on to the teachers by the parents before their child returns to school.

Since September 1981 a school doctor has participated regularly in the weekly diabetic clinic at the hospital. This has provided a valuable link between hospital, community, and school to the benefit of the diabetic child and family.

This study was designed to assess the diabetic knowledge of teachers of diabetic children. They were asked about their sources of information and an attempt was made to judge their interest in further education. Consideration was given to the best methods of informing teachers about diabetes given the limited resources available.

\section{Method}

The survey was based on the 60 diabetic children attending schools run by Liverpool Education Authority and the diabetic clinic at this hospital. Eighteen of the children attended 13 primary schools and 42 attended 27 secondary schools. For each primary school child the head teacher and the child's class teacher were invited to participate. In the secondary schools the head teacher and those teachers responsible for the class or year, physical education, and pastoral care were asked to take part.

A questionnaire was distributed to teachers by one of the authors (A J B) or by the appropriate school doctor or nurse. Teachers who had contact with more than 1 diabetic child were asked to complete a single questionnaire as the questions related to diabetes rather than to specific children. Questionnaires were sent to 132 teachers and 97 were completed.

The questionnaire was in 3 sections. In the first, basic information was collected about teaching experience, subject taught, position in school, knowledge of any diabetics other than children in 
school, whether teachers were concerned about having a diabetic child in their school or class, and details of any anxieties about diabetes in children.

In the second section teachers were given a list of possible sources of information. They were asked to indicate from which, if any, they had obtained information and whether they had seen the BDA or Alder Hey leaflets. They were also asked if they would like to learn more about diabetes and, if so, to suggest how this might be achieved.

The third section consisted of 18 questions related to diabetes, relevant to the school environment or to a teacher's understanding of the problems of the diabetic child. In each case the teacher had to choose between two alternative answers or 'not sure' (this option was included to reduce the incidence of guessing).

Teachers were asked not to consult books or colleagues when completing the questionnaire. Statistical methods used in the analysis of results included the student's $t$ test, $\chi^{2}$ test with Yates's correction and the calculation of rank correlation coefficients.

\section{Results}

The number of questionnaires distributed to and returned by the groups of teachers is shown in Table 1. The overall return was 97 of $132(73.5 \%)$ and 56 of the teachers responding were acquainted with diabetics other than the children in the school.

Twenty two teachers admitted anxiety about having a diabetic child in their class. Eleven were uneasy about the possibility of acute illness while in school and some expressed uncertainty about their ability to cope should such a situation arise. Two indicated that they would be worried only if they knew that the child's diabetic control was unstable. Two were concerned about the possibility of academic failure and 2 physical education teachers mentioned the possible effects of exercise. One teacher had not been worried until he read the questionnaire and realised the limitations of his

Table 1 Questionnaires distributed and returned

\begin{tabular}{lll}
\hline Status of teacher & Distributed & Returned (\%) \\
\hline Primary head teachers & 13 & 11 \\
Primary class teachers & 18 & 14 \\
$\begin{array}{l}\text { Secondary head teachers } \\
\begin{array}{l}\text { Secondary class, year, or } \\
\text { pastoral care teachers }\end{array}\end{array}$ & 27 & 22 \\
$\begin{array}{l}\text { Secondary physical education } \\
\text { teachers }\end{array}$ & 44 & 37 \\
Total & 30 & 13 \\
\hline
\end{tabular}

Table 2 Number of teachers receiving information from various sources

\begin{tabular}{lc}
\hline Source & No \\
\hline Child's parent & 52 \\
Newspapers or magazines & 40 \\
Child & 37 \\
Other school staff & 33 \\
Friends & 25 \\
Radio or television & 25 \\
Medical literature & 22 \\
School nurse & 21 \\
BDA/hospital leaflets & 20 \\
Own relatives & 20 \\
School doctor & 14 \\
Teaching literature & 13 \\
During teacher training & 10 \\
Hospital doctor & 8 \\
Diabetic health visitor & 5 \\
Dietician & 4 \\
Postgraduate teacher education & 4 \\
Child's general practitioner & 2 \\
School health service office & 1 \\
Other & 18 \\
\hline
\end{tabular}

knowledge. Teachers with more than 20 years' teaching experience were significantly less likely to express anxiety than those with less experience $\left(\chi^{2}=6 \cdot 623,0.02>P>0.01\right)$.

Table 2 shows the number of teachers receiving information from various sources suggesied to them. The number of sources of information per teacher ranged from 0 to 10 (mean 3.86). Additional sources of information mentioned by teachers included first aid courses (4) and the educational psychologist (1).

In response to the question 'Would you think it helpful to have more information on diabetes and its treatment in relation to the school child?', 91 teachers felt that it would, 4 did not want further information, and 2 did not respond. Most teachers (67) felt that the best way of supplying information was by means of literature. Many specified that it must be brief. Other suggestions included in-service courses or talks (18) or visits by health professionals (16). Several teachers asked for information on the recognition and treatment of diabetic emergencies.

Table 3 shows the questions included in the factual knowledge section of the questionnaire and the number of teachers giving the correct answer to each question. The mean score out of $\mathbf{1 8}$ for all teachers was 10.4 (range 1 to 17). There were no appreciable differences in total scores when teachers were grouped according to age, number of years teaching, position, or type of school. The mean score of science and biology teachers $(14 \cdot 13)$ was significantly higher than the mean score for other teachers $(9.92)$ $(P<0.01)$. Teachers who knew other diabetics scored significantly higher (mean 11.3) than those who did not $(9 \cdot 2)(P<0 \cdot 01)$. The total score did not appear to be related to the teachers' anxiety about having a diabetic in their class but was related to the 
Table 3 Factual knowledge questions and number of teachers giving correct answer*

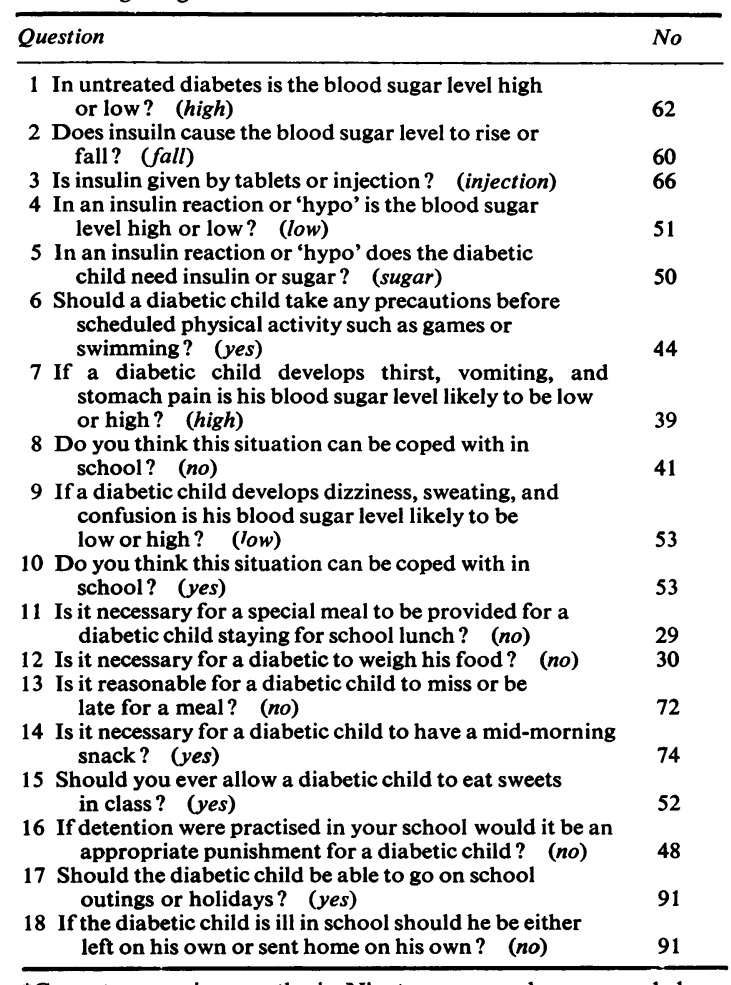

*Correct answer in parenthesis. Ninety seven teachers responded.

number of sources of information acknowledged by the teachers (Kendall rank correlation coefficient $=0.3 ; P<0.001$ ). In relation to question 6 , teachers who answered that special precautions were needed before exercise were asked to be more specific about those precautions. Correct answers were given by $65.9 \%$ of these teachers.

\section{Discussion}

It is generally agreed that diabetic patients of all ages should be helped and encouraged to live a life which differs as little as possible from that of people who do not have diabetes. This is particularly important for diabetic children who may be very conscious of the fact that they are different from their peers. Any differences that exist must be minimised, and to achieve this a good understanding of diabetes and its management is essential for the child and his parents. Several studies have looked at this aspect of the problem. ${ }^{3-6}$

Children spend a considerable amount of time in school and it is not unreasonable to expect their teachers to have a basic working knowledge of diabetes if life at school is to be safe and tolerable. Younger children may not be adept at dealing with problems such as hypoglycaemia and will be dependent upon the adult caring for them at the time; which in school time is the teacher. The ability to deal with this sort of problem is important not only to the diabetic child but to the rest of the class since a poorly managed episode might be generally disturbing. Teachers need to be aware of the dietary needs of diabetic children and of the need to take extra carbohydrate before exercise. They also need to understand the implications of diabetes to a child and his family if they are to deal effectively with the various problems that may arise.

We know of no British studies on the knowledge and attitudes of teachers. A study in Israel, ${ }^{7}$ while not asking about teachers' factual knowledge in detail, showed that most teachers received very little information about their diabetic pupils and regarded their knowledge as 'superficial'. In Cuba, Alvisa et al. ${ }^{8}$ found that only $36 \%$ of teachers understood the nature of diabetes, $21 \%$ understood its social implications, and only $16 \%$ would have been able to offer adequate care in cases of emergency. A study in Sweden ${ }^{9}$ showed that teachers had insufficient knowledge of diabetes and the management of hypoglycaemia, and 60 to $80 \%$ of these teachers considered their knowledge insufficient to deal with diabetic pupils. These studies indicate both a lack ofô diabetic knowledge and the inadequacy of: information offered to teachers.

In the diabetic clinic at this hospital, before 1981, schools were informed about their diabetic pupils primarily by means of clinic leaflets passed on by parents. While hospital medical and nursing staff and dieticians have always been available to deal with enquiries from school staff no systematic attempt was made to contact schools or to educate teachers about diabetes. The addition of the services of 2 diabetic health visitors made more contact with the schools possible, although the basic means of informing schools remained unchanged. There was no close link with the school health service until October 1981 when a school doctor was attached to the clinic team. In addition to taking part in the diabetic clinic he was also in a position to visit schools more often than had previously been possible and an opportunity arose to assess the extent of teachers' knowledge of diabetes and how teacher education might be improved in the future.

The survey showed that the factual knowledge of teachers about diabetes was limited. The total scores were extremely variable and it is difficult to know what score should be regarded as acceptable. The questions were chosen to be relevant to a child's school life or to an understanding of the problems 
experienced by a diabetic child. Therefore, a fairly high score might be expected from a well informed teacher. Ludvigsson ${ }^{9}$ regarded a score of $75 \%$ in his survey as showing 'adequate knowledge' and this would be roughly equivalent to a score of 14 or more in our study. Only 24 teachers achieved this score indicating that 73 had inadequate knowledge, and the true situation may be worse as some correct answers may have derived from guesswork. A lack of understanding may be detected by looking at the answers to certain pairs of questions. For example, some teachers who correctly identified the symptoms of hypoglycaemia or hyperglycaemia were not able to say correctly which of these could be managed at school or did not know the correct treatment for hypoglycaemia. Others apparently knowing the importance of regular meals did not appreciate the possible risk of detaining a child after school. Similarly $44(45.4 \%)$ teachers knew that special precautions were necessary before exercise but only $29(29.9 \%)$ were able to give details of these precautions. Other factors that may have improved the scores include the leading nature of some of the questions and the possibility that the 35 teachers who did not complete the questionnaire might include teachers whose knowledge and interest was particularly poor.

It is encouraging to note from questionnaire answers that teachers appreciate the need for diabetic children to take part in school outings and holidays and were aware of the dangers of leaving a sick diabetic child alone. The need for regular meals and snacks was widely known, although other aspects of dietary management were less well known, perhaps because these are more relevant to catering staff than to teachers.

Questions relating to recognition of hypoglycaemia and hyperglycaemia and their treatment were particularly badly answered-more so when inconsistent answers to different questions are taken into account. Superficial understanding of hyperglycaemia is acceptable for teachers but they should be able to recognise and treat hypoglycaemia if serious problems are to be avoided. Fourteen teachers answered all the questions on both problems correctly and 29 scored full marks on hypoglycaemia.

Our results show a disappointing lack of knowledge and raise the question of how teachers should be informed. Our findings are in broad agreement with those of other workers in that many teachers feel they have not received sufficient information on the subject. The most common source of information was the child and his parents. Other studies on the knowledge of children and their parents suggest that this source of information is likely to be less than adequate and may in some cases be positively misleading. Other school staff and friends or relatives of the teachers were common sources of information, again possibly of limited value. Information from the media may well be of a rather superficial nature.

There are many possible reasons for only 20 of 97 teachers having seen the leaflets distributed from the clinic. Parents or teachers may have lost the leaflets. They may have been taken to school initially but not passed on as the child moved up the school. Since one child may be taught by many teachers perhaps leaflets were not distributed in sufficient numbers. Clearly, for whatever reason, this method of communication has not been very successful. Despite this most teachers felt that the use of printed material was the most appropriate means of getting information to them. The method of distribution needs to be improved and it seems unwise to rely on parents for this important function.

The most striking point from Table 2 is the relative lack of involvement of professional health workers. School nurses may have the most contact with teachers but only 20 teachers had received information from them. Medical staff were even less in evidence as sources of information. The dieticians may have played a more important role than this survey reflects since their contact tends to be with school catering staff rather than with teaching staff.

Printed leaflets may continue to be the main means of disseminating information to schools and those we use at present which cover most points explored in the questionnaire require little modification. The major problem is that of distribution, and the leaflets clearly need to be sent directly to the schools in sufficient numbers. Head teachers should be responsible for drawing the attention of other staff to them, particularly when a child changes class. In addition we suggest that when diabetes is diagnosed and where a school doctor is available for the task, a personal visit should be made with parental consent to the school. The problem may then be discussed in some detail with teachers. Other members of the diabetic team may take part in this initial exercise with perhaps repeat visits in later years if necessary. Follow up visits would be particularly useful when a child changes schools, although if this became routine practice it would entail considerable extra work at the beginning of each school year.

Our results suggest that teachers' knowledge increases with the addition of more sources of information. This might to some extent be achieved by the means outlined above. In addition it is desirable to improve the expertise of all school doctors and nurses and to encourage them to discuss their diabetic patients when visiting schools. More use may be made of the flip chart 'Index of 
first aid and health problems for schools' which is 'References

used in Scottish schools and is less likely to be lost than leaflets on a single condition. Informal discussions with teachers and their response to this survey suggest that they are keen to participate and are receptive to information offered to them in a suitable way. More education on health problems, including diabetes, should be included in teacher training programmes.

The approach suggested is not entirely new. Farquhar and Campbell ${ }^{10}$ reported their close links with schools and claimed that their use of a home care team was beneficial. They pointed out, however, that the benefits are difficult to quantify. We have shown that our current practice is not effective in terms of teacher education and it remains to be seen whether it can be improved by a more intensive approach. The next and more difficult stage, will be to determine the effect of improved teacher education on the happiness and achievements of diabetic children in school.

The results of this survey underline the inadequate education and liaison of professional groups caring for children with a chronic disease, namely diabetes mellitus. The results may simply reflect the failings of our local system but we suspect that they represent a national problem that is not confined only to children with diabetes mellitus.

We thank Drs P Pinkerton and P Harker for assistance in preparing the questionnaire, the school doctors and nurses who helped in its distribution, and all the teachers who took part.

1 Calnan M, Peckham CS. Incidence of insulin-dependent diabetes in the first sixteen years of life. Lancet $1977 ; \mathbf{i}$ : 589-90.

2 Fitzherbert K. Communication with teachers in the health surveillance of school children. Maternal and Child Health $1982 ; 7: 100-3$.

3 Ludvigsson J. Socio-psychological factors and metabolic control in juvenile diabetes. Acta Paediatr Scand 1977; 66:431-7.

4 Collier BN, Jr, Etzwiler DD. Comparative study of diabetes knowledge among juvenile diabetics and their parents. Diabetes $1971 ; 20: 51-7$.

5 Etzwiler DD. What the juvenile diabetic knows about his disease. Pediatrics 1962;29:135-41.

${ }^{6}$ Etzwiler DD, Sines LK. Juvenile diabetes and its management: family, social and academic implications. JAMA $1962 ; 181: 304-8$.

7 Frankel JJ. Academic performance of juvenile diabetics and teachers' attitudes. In: Laron Z, ed. Habilitation and rehabilitation of juvenile diabetics. Leiden: HE Stenfert, Kroese NV: 1970:93-102.

8 Alvisa R, Barroso C, Güell R, Márquez A, Mateo-deAcosta $O$. Scholastic situation of the juvenile diabetic. Acta Diabetol Lat 1974;11:250-7.

${ }^{9}$ Ludvigsson J. Diabetics in school-knowledge and attitudes of school staff in relation to juvenile diabetics. Scand J Soc Med 1977;5:21-30.

10 Farquhar JW, Campbell ML. Care of the diabetic child is the community. Br Med J 1980;281:1534-7.

Correspondence to Dr C S Smith, Department of Child Health, Alder Hey Children's Hospital, Eaton Road, Liverpool L12 2AP.

Received 22 April 1983 